Konstanzer Online-Publikations-System (KOPS)

URL: http://www.ub.uni-konstanz.de/kops/volltexte/2007/3930/

URN: http://nbn-resolving.de/urn:nbn:de:bsz:352-opus-39304

\title{
Review
}

\section{Scaffolding microdomains and beyond: the function of reggie/flotillin proteins}

\author{
M. F. Langhorst*, A. Reuter and C.A. O. Stuermer \\ Developmental Neurobiology Group, Department of Biology, University of Konstanz, Universitätstrasse 10, \\ 78457 Konstanz (Germany), Fax: +49 7531 883894, e-mail: Matthiaslanghorst@email.de
}

Received 22 April 2005; received after revision 20 May 2005; accepted 22 June 2005

Online First 9 August 2005

\begin{abstract}
Reggie/flotillin proteins are considered to be components of lipid rafts and are commonly used as marker proteins for lipid microdomains. Yet almost a decade after their discovery, the function of reggies/ flotillins is still enigmatic. In this review we summarize the present state of knowledge on reggie/flotillin structure, localization and function, and discuss the role of the proteins in development and disease. Based on insights into reggie/flotillin function and by comparison with related proteins of the so-called SPFH (․tomatin/Prohibitin/
\end{abstract}

Flotillin/ $\underline{\mathrm{H} f l K} / \mathrm{C})$ protein family, including stomatin, podocin and prohibitin, we propose the existence of specific types of protein-defined microdomains which are sculpt by the clustering of individual SPFH proteins. As 'specialized rafts' similar to caveolae, these membrane domains provide platforms for the recruitment of multiprotein complexes. Since, under certain circumstances, reggie-2/flotillin-1 translocates to the nucleus, reggie/ flotillin microdomains are not only stable scaffolds but also dynamic units with their own regulatory functions.

Key words. Lipid raft microdomains; signaling scaffolds; actin cytoskeleton; SPFH domain; stomatin; podocin; prohibitin; caveolae.

\section{Discovery of reggie/flotillins}

'Third time is a charm' the saying goes, and accordingly, reggie/flotillin proteins were independently 'discovered' three times. Madeleine Duvic and co-workers were the very first to discover part of one of the proteins during a screen for the antigen of the monoclonal antibody ECS-1 in 1994. They identified a complementary DNA (cDNA) coding for a N-terminally truncated version of reggie1/flotillin-2 of $42 \mathrm{kDa}$ (see below), which they called epidermal surface antigen (ESA) [1]. This name was later abandoned, as it was shown that this protein is not the true antigen recognized by ECS-1 [2]. In a screen for proteins upregulated in retinal ganglion cells during axon regeneration after optic nerve lesion in goldfish, we identified in

* Corresponding author.
1997 two proteins of $47 \mathrm{kDa}$ which we called reggie-1 and $-2[3,4]$. In the same year Michael Lisanti's group identified two proteins associated with the 'floating' lipid raft fraction from mouse lung tissue which they called flotillin-1 (= reggie-2) and flotillin-2 (= reggie-1) [5]. Although flotillins became the more commonly used name for the proteins, we will stick with reggie-1 and -2, since we believe that our names and numbers are more appropriate in light of the physiological relevance of the two proteins.

\section{Structure of reggies}

Reggie proteins are highly conserved, with about 64\% homology between fly and man $[6,7]$. Reggie-like proteins even exist in some bacteria, plants and fungi $[8,9]$. 


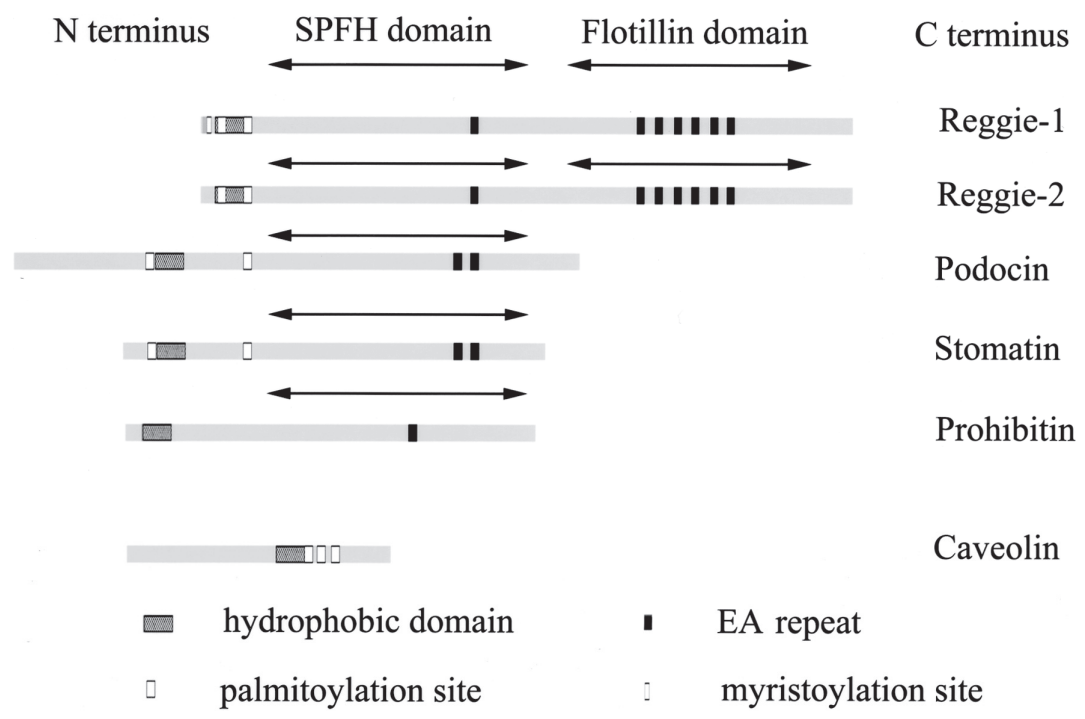

Figure 1. Alignment of reggie-1 and -2 with SPFH proteins and comparison with caveolin. The SPFH and flotillin domains are indicated; acylation sites, hydrophobic domains and EA repeats are shown as structural features.

In humans, the gene encoding reggie-1 is located on chromosome 17 (17q11-12) [10]. It is a single-copy gene consisting of 11 exons giving rise to a protein of $47 \mathrm{kDa}$. The human reggie-2 gene is a single-copy gene located on chromosome 6 (6p21.3). It encompasses $15 \mathrm{~kb}$ with 13 exons coding for a protein of $47 \mathrm{kDa}$ [8]. Reggies are considered to belong to the SPFH (Stomatin/Prohibitin/ Flotillin/flK/C) protein superfamily, whose members share a domain of similar sequence but unknown function, the so-called SPFH domain at their N-terminus [11]. In contrast to other $\mathrm{SPFH}$ proteins, the $\mathrm{C}$-terminus of reggies harbors a unique flotillin domain, which is characterized by several repeats of glutamic acid and alanine (EA repeats) and which is predicted to potentially form coiled coil structures (fig. 1) [1,5].

In contrast to earlier reports, reggies do not possess a transmembrane domain. Both $\mathrm{C}$ - and N-termini face the cytosol $[12,13]$; the hydrophobic region might interact with but apparently does not span the membrane. Anchoring to the cytoplasmic leaflet of membranes is accomplished by acylation. Reggie-1 is myristoylated at Gly2 and palmitoylated mainly at Cys4 and to a minor degree at Cys19 and Cys20 [14]. Reggie-2 lacks a myristoylation site but is palmitoylated at Cys34 [12] and potentially also at Cys5 and Cys17.

Recently, the three-dimensional structure of the SPFH domain of reggie-1 was solved [15] and is available in MMDB [16]. This structure encompasses the region from aa 43 to aa 173 and indicates that the SPFH domain of reggies is a compact, ellipsoid-globular structure containing four to five alpha helices and six beta strands. The flotillin domain, which has not yet been solved, is predicted to harbor several alpha helices, some of which might be involved in coiled coil formation.
The C-terminal part of reggie-1 is essential for the formation of homo- and most probably also heterooligomers ([14] and our own unpublished observations) which may be mediated by coiled coils in the region of the EA repeats. Chemical cross-linking experiments demonstrated that the smallest building block of reggie oligomers are tetramers; smaller oligomers are not detectable [G. Solis and C. A. O. Stuermer, unpublished observations].

The initial description of reggie- 1 as a $42-\mathrm{kDa}$ cytosolic protein raises the question whether this and perhaps other splice variants exist. Indeed, expressed sequence tag (EST) database searches yield multiple tags for this Nterminally truncated form lacking the membrane anchor. However, we and others have not found any major splice variants of reggie-1 in western blots or reverse transcription-polymerase chain reactions (RT-PCRs) of various mammalian cell lines or tissues $[8,17]$. In a recent report, a splice variant of reggie-2 based on ESTs was proposed, which lacks exon 4 [18]; but again, a major expression of such a variant in mammalian cells has so far never been observed. However, two variants of reggie-1 were recently reported in Drosophila, differing in 39 bp encoded by a short, alternatively spliced exon. These two splice variants are differentially expressed during development, with the longer form being predominantly expressed during embryonic and larval development, while the shorter variant predominates in the adult fly [M. Hoehne, H. G. de Couet, C. A. O. Stuermer and K. F. Fischbach, unpublished observations].

Due to sequence similarities reggies are considered members of the SPFH protein family, including stomatin, podocin, prohibitin and the bacterial $\mathrm{HflK} / \mathrm{HflC}$ proteins [11]. A recent analysis of the evolutionary relationships 
between all SPFH proteins showed that the observed sequence similarities in the SPFH domain must have arisen by convergent evolution [E. Rivera-Milla, C. A. O. Stuermer and E. Malaga-Trillo, unpublished observations]. Several structural hallmarks are remarkably similar among all SPFH proteins (fig. 1). They share a hydrophobic domain in their N-terminus which is often preceeded by a palmitoylation site. In case of reggies, stomatin and podocin, this hydrophobic domain does not span the membrane but is suggested to form a horseshoelike structure, with both $\mathrm{N}$ - and C-termini facing the cytosol [12, 13, 19-21], while prohibitin possesses a transmembrane domain. Similarly, all SPFH proteins share a stretch of EA repeats in their C-termini, which is extended by the flotillin domain in case of reggies. The first EA repeat at the end of the SPFH domain (the only EA repeat in other SPFH proteins) was shown to be essential for oligomerization of stomatin [22]. The formation of oligomers is another hallmark shared by all SPFH proteins. Oligomers were shown for stomatin [22], podocin [21] prohibitin [23, 24] and reggies [14].

These similar structural features suggest a related function for all SPFH proteins. Considering their widespread distribution, their function is supposed to be basic and important. Interestingly, the structural hallmarks described above are reminiscent of an unrelated protein caveolin. Although quite different in domain structure, caveolin is predicted to adopt a hairpin-like structure with a central hydrophobic domain interacting with but not spanning the membrane, and both $\mathrm{N}$ - and C-termini facing the cytosol [25]. It is palmitoylated on multiple cysteine residues [26], and it forms oligomers [27]. These oligomers are supposed to form the structural scaffold of caveolae, a well-defined subtype of lipid microdomains important for signaling, specialized endocytotic processes and transcytosis [28].

\section{Subcellular localization and trafficking of reggies}

In single cells reggies are most prominently found at the plasma membrane, where they associate with the inner leaflet via acylations (fig. 2A) [14]. Being insoluble in Triton-X-100 and other commonly used non-ionic detergents at $4{ }^{\circ} \mathrm{C}$, reggies are considered bona fide raft proteins and are often used as raft markers. But unlike many other proteins considered to be raft-associated, reggies form stable clusters at the plasma membrane readily observable by electron microscopy and immunogold or diaminodenzidine (DAB)-based staining (fig. 2B) [4, 29, 30]. Reggie clusters are surprisingly uniform in size, with an estimated diameter of $100 \mathrm{~nm}[29,30]$, and consist most probably of reggie-1 and -2 homo- and heterooligomers. They are quite widely spaced along most of the plasma membrane but become more closely spaced at cell-cell contact sites and after crosslinking of associated cell surface molecules such as glycosylphosphatidylinositol (GPI)-anchored Thy-1 or $\operatorname{PrP}^{\mathrm{c}}[29,31]$.

Although it was repeatedly claimed that reggies reside within caveolae [5,32], we and others have convincingly shown that reggie clusters are distinct from caveolae. First of all, reggies are expressed and reggie clusters are detected in cell types which do not express any caveolins - most importantly neurons and lymphocytes [4, 29]; caveolins and reggies show distinct expression patterns both in adult tissues [33] and in developing organisms [34]. Even in cells that do express both caveolin and reggies, reggie microdomains are clearly distinct and located outside of caveolae [4, 29, 35].

In addition to their preferred localization at the plasma membrane, reggies can be found at various vesicular compartments inside the cell. In many cell types, a prominent localization of both reggie proteins at the pericentrosomal region is observed, sometimes overlapping with recycling endosomes (fig 2A) $([17,36]$ and our own unpublished observations). Reggies also co-localize with markers for lysosomes [31] and are found in multi-vesicular bodies [37, 38]. Like other raft-associated proteins, they also localize to lipid-rich droplets (lipid bodies) $[39,40]$.

Although the localization pattern of reggie- 1 and -2 is largely overlapping in many cell types, specific differences in some cell types and on particular organelles are observed. In many cells, reggie- 2 is found more prominently on intracellular organelles than reggie-1. In 3T3 fibroblasts, reggie-2 is predominantly found on intracellular granules but relocates to the plasma membrane upon differentiation to adipocytes [41]. Similarly, in RAW 264.7 macrophages (which despite a contrary report [42] express both reggies), reggie-2 is almost exclusively found on intracellular vesicular organelles while reggie-1 is found predominantly at the plasma membrane [our own unpublished observations]. In phagocytic cells reggie-2 was also observed on phagosomes [43], where it accumulates during maturation of the phagosome by fusion with endosomes [44]. The most important difference concerning the localization of the two reggies seems to be the translocation of reggie-2 to the nucleus. In a recent report, Santamaria et al. have described a cell-cycle-dependent translocation of reggie-2 and PTOV-1 to the nucleus, the nuclear localization of both proteins being most pronounced at the beginning of S-phase [45]. Reggie-1, however, was not observed to translocate to the nucleus in this study [45]. This matches our own observation that reggie- 2 can sporadically be found in the nucleus of e.g. PC12 cells [our own unpublished observations]. The function of reggie- 2 in the nucleus is currently unclear. It did not localize to any structure identifiable in the electron microscopy, but reggie overexpression had a mitogenic effect in PC3 cells [45]. 
A

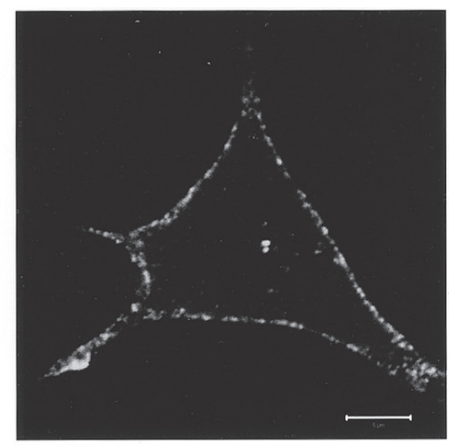

B

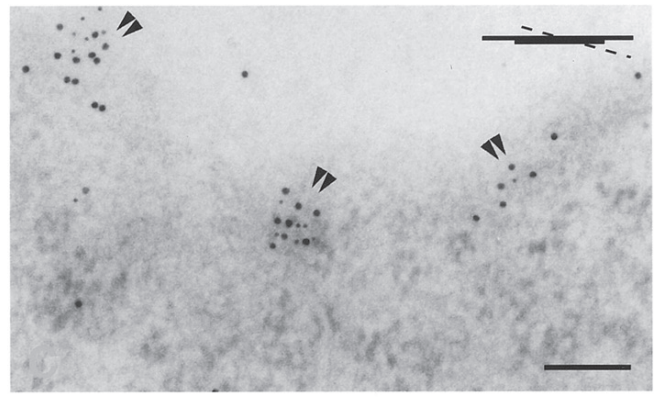

C

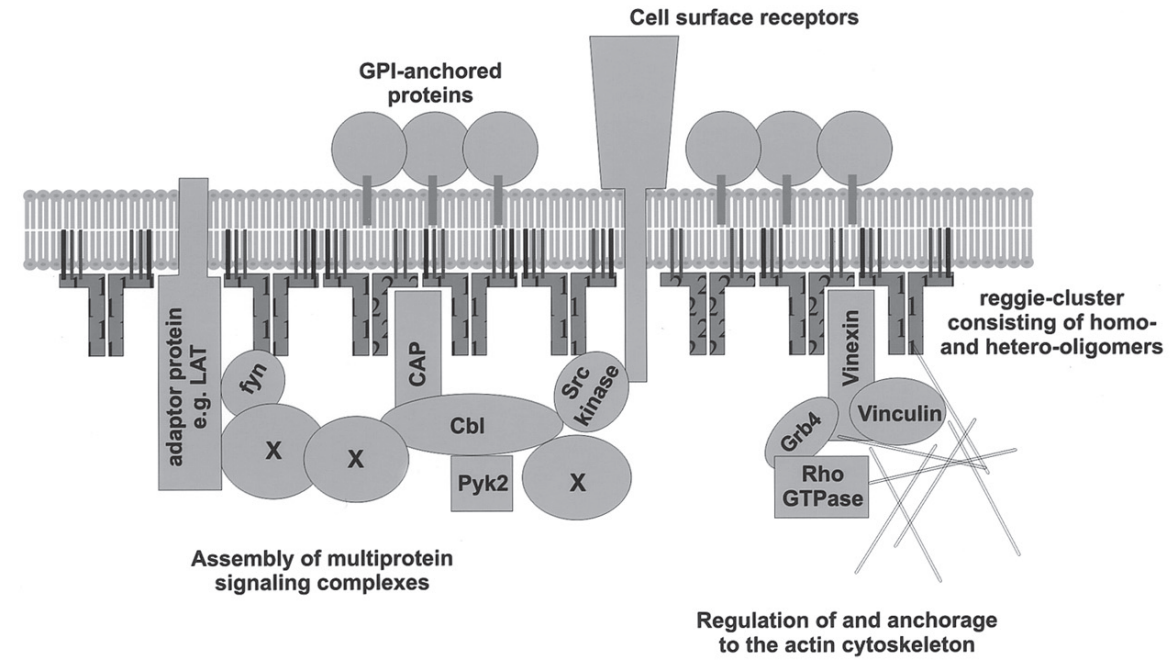

Figure 2. (A) Confocal image of a PC12 cell stained with monoclonal antibody against reggie-1. Reggie-1 is detected in puncta along the plasma membrane and additionally at the centrosome (bar, $5 \mu \mathrm{m}) ;(B)$ grazing section of the plasma membrane of a PC12 cell with double immunogold labeling of reggie-2 (10-nm gold grains) and GPI-anchored Thy-1 (5-nm gold grains) after in vivo crosslinking of Thy-1. Note the labeling of $\approx 0.1-\mu \mathrm{m}$-large microdomains, where both proteins are clustered (bar, $0.1 \mu \mathrm{m}$, reprinted from Molecular Biology of the Cell (Mol. Biol. Cell (2001) 12: 3031-3045) with permission by the American Society for Cell Biology); (C) model of reggie scaffolds with associated proteins. Reggie oligomers serve as stable scaffolds for multiprotein complex assembly. The reggie clusters are anchored to the actin cytoskeleton but also recruit the machinery for regulation of the cytoskeleton.

Taken together, these data suggest that reggie-1, being irreversibly myristoylated, is the more immobile of the two, residing predominantly at the plasma membrane. The reversibly palmitoylated reggie- 2 , on the other hand, seems to be more versatile, shuttling between the plasma membrane and various intracellular organelles. Thus, the common usage of reggie-2/flotillin-1 as a marker protein for plasma membrane lipid rafts is questionable.

Conflicting reports exist about the biosynthetic pathway of reggies. Gkantiragas et al. described sphingomyelinenriched microdomains at the Golgi complex in NRK, $\mathrm{CHO}$ and HeLa cells which contained reggie-2 [13]. Reggie-2 localization at the plasma membrane was shown to be Brefeldin A-sensitive, indicating that reggie-2 travels through the Golgi in its biosynthetic pathway and becomes detergent-resistant on its way. However, Morrow et al. showed that trafficking of reggie-2 is Brefeldin Aand Sar1-insensitive in BHK cells [12], suggesting a Golgi-independent trafficking pathway similar to K-Ras,
F3/Contactin or TC10 [46-48]. Reggie-1 trafficking is BFA-sensitive in Jurkat T and PC12 cells, and although overexpressed full-length protein localizes to the Golgi complex only to a minor extent, mutants with deletions in the SPFH domain accumulate in the region of the Golgi complex [our own unpublished observations]. Due to their relatively small size and lack of transmembrane domains or signal sequences, reggies associate with membranes via co- or post-translational modifications such as reversible palmitoylation and, in case of reggie-1, myristoylation. So it is conceivable that reggies might use both Golgi-dependent and -independent vesicular or even nonvesicular pathways to reach the plasma membrane or other intracellular membranes.

Very little is known about the endocytic trafficking of reggies. Although they are localized at recycling endosomes [36], lysosomes and multivesicular bodies [31,37, 38], we so far never succeeded in capturing and characterizing the first transient events of a presumptive vesic- 
ular endocytosis. They do not localize to clathrin-coated pits, even after cross-linking of associated cell surface molecules which are contained in coated pits, and they are not found in EEA-1-positive early endosomes either at the electron or light microscopic level in various cell types [our own unpublished observations]. But given their prominent localization on vesicular compartments implicated in recycling, they might use a non-conventional endocytic pathway.

There are several ways by which reggie localization might be regulated. The reversibility of palmitoylation [49] of both reggies can regulate their affinity for membranes, especially in case of reggie-2, which is not myristoylated. Moreover, reggie function might be regulated by proteolytic cleavage, since calpain-mediated cleavage of reggie-1 but not reggie-2 in platelets was reported [50].

\section{Tissue distribution and expression during development}

All stable cell lines we have tested so far express at least reggie-1. Reggie-2 exhibits a more restricted expression, but is still widely expressed. The stability of reggie- 2 is strongly linked to the presence of reggie-1, as downregulation of reggie-1 by specific small interfering RNAs (siRNAs) in mammalian cell lines reduces protein levels of reggie-2. On the other hand, siRNAs-mediated knockdown of reggie-2 does not impair reggie-1 stability [M. Hoegg, A. Reuter, M. F. Langhorst et al., unpublished observations]. Furthermore, Drosophila reggie-1 knock-out mutants lose reggie-2 protein [M. Hoehne, H. G. de Couet, C. A. O. Stuermer and K. F. Fischbach, unpublished observations]. These observations suggest that the stability of reggie-2 requires the presence of reggie-1, but reggie-1 can exist without reggie-2.

Expression of reggies during differentiation was investigated in several cell culture models. In $3 \mathrm{~T} 3$ fibroblasts reggie-2 expression is apparently upregulated during the formation of cell-cell contacts [18]. Differentiation of osteoclasts induces strong upregulation of reggie-2 expression [51]. Reggie-1 expression is upregulated during in vitro differentiation of $\mathrm{C} 2 \mathrm{C} 12$ skeletal myoblasts [32]. During differentiation of 3T3 fibroblasts to adipocytes, reggie-2 expression is enhanced while reggie-1 expression remains unchanged [5], and reggie-2 translocates from intracellular compartments to the plasma membrane [41]. In contrast, differentiation of PC12 cells does not affect the expression of either reggie [32]. Thus, reggie expression seems to increase during differentiation of various cells in culture. Moreover, both reggies are strongly upregulated by retinal ganglion cells during axon regeneration after optic nerve lesion $[3,4]$.
There are only two comprehensive reports on reggie expression during development in vertebrates. Due to genome duplication in fish, there are two copies of each reggie gene in zebrafish [7], but one reggie-1 gene was rendered non-functional during evolution. In good correlation to the ubiquitous expression in stable cell lines, reggie- $1 \mathrm{a}$, reggie- $2 \mathrm{a}$ and $-2 \mathrm{~b}$ are expressed ubiquitously during the early stages of zebrafish development [52]. Upon segmentation, the expression pattern becomes more restricted. Reggie-2a is expressed in differentiating neurons in the brain, spinal cord and neurogenic placodes, while reggie- $2 b$ is expressed in head mesoderm, neural crest derivatives and along somite boundaries. Reggie-1a is highly expressed in domains overlapping with the expression pattern of both reggie-2 genes, except at the somites where it complements the pattern of reggie2 b. Immunostainings using reggie antibodies stain all fiber tracts in the developing nervous system [52], indicating involvement of reggie-1a and -2a in neuronal differentiation as expected, due to their identification in regenerating axons.

Morpholino knock-down of reggie expression in the developing zebrafish leads to severe morphological defects starting early during gastrulation. This emphasizes the important role of reggies during early development [E. Riviera-Milla, E. Malaga-Trillo and C. A. O. Stuermer, unpublished observations].

An expression pattern similar to the one observed in zebrafish was reported for reggie-2 in the developing Xenopus [34]. Due to the partial duplication of the Xenopus laevis genome, there are also two copies of the reggie-2 gene in frogs. Both genes are highly and ubiquitously expressed during early stages of development. During neural plate formation, expression is enhanced in the neural ectoderm and later on in the neural tube. From late tailbud stages on, the two reggie- 2 genes are differentially expressed. Flotillin-1a (reggie-2a) is expressed in several neural crest derivates, including the olfactory pit and cranial ganglia, and in the dorsal regions of the neural tube, including the primary neurons in the dorsal spinal cord. Flotillin-1b (reggie-2b) expression is restricted to small domains of the dorsal neural tube, and a low level of expression is found in the branchial arches [34]. Unfortunately, the expression pattern of reggie-1 was not investigated in this study.

In Drosophila, reggie-1 and - 2 are highly expressed in the developing and adult nervous system [6] with particularly high expression in axons at the root of fiber tracts where strong fasciculation is required. Misexpression of reggie1 and -2 in the eye imaginal disc leads to severe mistargeting of specific cell-adhesion molecules of the immunglobulin superfamily (IgCAMs), resulting in an irregular ommatidial pattern. Similarly, misexpression in the wing imaginal disc leads to extension of the wingless signal and disrupts normal wing development [M. Hoehne, 
H. G. de Couet, C. A. O. Stuermer and K. F. Fischbach, unpublished observations].

There are no comprehensive studies on the expression of reggies in adult organisms, but reggie-1 is apparently widely expressed in many different tissues, with particularly high expression in brain, while reggie- 2 expression is slightly more restricted $[5,32,52]$.

In summary, reggie expression seems to be essential for all cells in culture and during early stages of development. The available data on interference with reggie function during development from zebrafish and flies point to an important role of reggies in regulating formation of correct cell-cell contacts during morphogenesis. During later developmental stages and in the adult organism, reggies are still widely expressed but with a particularly high expression in the central nervous system.

\section{Cellular function of reggie proteins}

Despite their ubiquitous expression and their evolutionarily high conservation, the function of reggies is still unclear. They have been implicated in signal transduction, vesicle trafficking and cytoskeleton rearrangement, and a variety of proteins have been shown to interact with reggies.

Reggies were isolated by co-immunoprecipitation with the monoclonal antibody M802, which was later shown to recognize the fish homologue of Thy-1 [3, 4, 53]. Fish Thy- 1 co-localizes with reggies [54]. The close association with Thy-1 is conserved in different mammalian cell types such as PC12 and lymphocytes [29]. Remarkably, reggies also co-localize and can be co-immunoprecipitated with other GPI-anchored proteins, such as F3/contactin [29] and $\operatorname{PrP}^{\mathrm{c}}$ [31]. This suggests involvement of reggies in signal transduction by GPI-anchored proteins across the plasma membrane. Accordingly, reggies seem to be quite closely associated with the Src-family kinases lck and fyn [29, 41, 42], as shown by both co-immunoprecipitation and co-localization at the light microscopic (LM) and electron microscopic (EM) level. Several large transmembrane proteins have also been co-immunoprecipitated with reggies, including $\mathrm{ABCA} 1$ [55], an $\mathrm{ABC}$ transporter implicated in cholesterol transport to highdensity lipoprotein particles. Co-immunoprecipitation of the thrombin receptor PAR-1 with reggie-1 from melanoma cell lines [56] and identification of an interaction between neuroglobin and reggie-2 in a yeast two-hybrid screen [57] suggest a function of reggies in G-protein-coupled receptor signaling.

Considering the identification of reggies as proteins upregulated during axon regeneration, control of cytoskeletal dynamics seems a good guess for reggie function. Indeed, overexpression of full-length reggie-1 or of the cytosolic $42-\mathrm{kDa}$ variant induces filopodia formation in several cell types $[2,14]$. A direct link between reggies and regulation of the actin cytoskeleton was reported by Kimura et al., who described the direct interaction between the sorbin homology ( $\mathrm{SoHo}$ ) domain present in adaptor proteins of the vinexin family and reggie-2 [58]. The vinexin family of adaptor proteins consists of vinexin- $\alpha$ and $-\beta, \mathrm{CAP} /$ ponsin (c-Cbl-associated protein) and ArgBP2 [59]. These ubiquitously expressed proteins are characterized by one SoHo domain at their N-terminus and three $\mathrm{SH} 3$ domains in their $\mathrm{C}$-terminal region. While the SoHo domain provides the means of membrane recruitment via its interaction with reggies, the vinexin family proteins bind to a variety of proteins via their $\mathrm{SH} 3$ domains, e.g. to the ubiquitin-ligase and adaptor protein $\mathrm{c}-\mathrm{Cbl}$, the tyrosine kinase $\mathrm{c}-\mathrm{Abl}$ and main regulators of cytoskeletal dynamics such as vinculin, afadin and the regulators of small GTPases Grb4 and Sos [59]. Thus, via interaction with vinexin family members, reggies might recruit multiprotein signaling complexes to membrane microdomains to direct cytoskeletal dynamics. Reggiedependent recruitment of a $\mathrm{CAP} / \mathrm{c}-\mathrm{Cbl}$ complex was shown to be essential for the insulin-receptor-stimulated insertion of Glut4 glucose transporters into the plasma membrane. CAP-mediated recruitment of $\mathrm{Cbl}$ into lipid rafts stimulates the cdc42 family GTPase TC10 via a CrkII-C3G complex, and this pathway necessarily amends the well-known phosphatidylinositol-3(PI3)-kinase-dependent signaling pathways downstream of the insulin receptor $[58,60]$. Similarly, the recruitment of a $\mathrm{Cbl} /$ Pyk2 complex to plasma membrane microdomains was shown to be essential for neuritogenesis in differentiating PC12 cells [61]. A role of reggies in the control of cytoskeletal remodeling might thus account for the observed upregulation of reggies during differentiation (see above).

Reggies seem to play an essential role in $\mathrm{T}$ cell activation by controlling the assembly of signaling complexes and cytoskeletal rearrangements necessary for prolonged signaling to occur after T-cell-receptor (TCR) stimulation. Both reggies are expressed in B and T lymphocytes [17, 29]. In T cells, reggie- 1 and -2 are associated with the Src-kinases lck and fyn as shown by co-immunoprecipitation [29, 31, 42, 62]. Reggie-2 binds fyn regardless of its activity, as it also binds to the kinase-dead mutant [41]. Furthermore, reggies are associated with the adaptor protein LAT [42]. The association with LAT and lck apparently increases after $\mathrm{CD} 3 / \mathrm{CD} 28$ co-stimulation of the cell; furthermore vimentin and IKK $\beta$ associate with reggie complexes after activation of the cell $[42,62]$. Both in stable cell lines and in peripheral lymphocytes, reggie-1 and -2 exhibit a strikingly polarized localization in resting cells, accumulating in one aspect of the cell forming a 'preformed cap' [31, 63]. Using fluorescence recovery after photobleaching (FRAP), we recently showed that reggie-1 is essentially immobilized in the region of the 
preformed cap, although it is highly mobile at the rest of the plasma membrane or at the plasma membrane of other cells [M. F. Langhorst, A. Reuter, G. Luxenhofer et al., unpublished observations]. The preformed reggie cap is therefore a stable preassembled platform conferring inherent polarity to these cells which are widely considered as unpolarized before activation. Stimulation of the cells by cross-linking of cell surface components leads to accumulation of signaling molecules such as lck, LAT and the TCR/CD3 complex in the region of the preformed reggie cap [31,63], reflecting the increased biochemical association. The assembly of the TCR signaling machinery is thought to be mediated by fusion of small, dynamic rafts into one stable macrodomain [64]. Translocation to the cap region and macrodomain assembly is an active process regulated by dynamic reorganization of the cytoskeleton [65-67]. Expression of a deletion construct that interferes with reggie oligomerization inhibits macrodomain assembly and leads to severe defects in cytoskeletal rearrangements induced by stimulation of the cell with a mitogenic lectin [M. F. Langhorst, A. Reuter, G. Luxenhofer et al., unpublished observations]. Thus, the preformed caps provided by reggies are an essential organizing center for $\mathrm{T}$ cell activation. They apparently act as priming platforms for macrodomain assembly and control the necessary remodeling of the cytoskeleton via their close association with fyn and potentially members of the vinexin family.

\section{Reggie proteins in health and disease}

Lipid rafts have been implicated in a variety of pathological conditions ranging from atherosclerosis to Ebola infection [68]. Entry of different viruses and other pathogens also occurs via lipid rafts, the most prominent example being the binding of human immunodeficiency virus (HIV) gp120 to CD4 and chemokine receptors, which leads first to raft clustering and then to fusion of the virus envelope with the plasma membrane. Considering the proposed functions of reggies, an involvement in pathogen entry seems very likely. Indeed, several reports implicate reggies in host cell invasion by Plasmodium. Invasion of erythrocytes by Plasmodium falciparum can be inhibited by cholesterol depletion, suggesting that lipid rafts are the site of invasion [69]. During formation of the parasitophorous vacuole (PV), several raft-associated proteins, such as CD59 and $\mathrm{G} \alpha_{\mathrm{s}}$, are recruited from the plasma membrane of the host cell to the PV membrane [70]. Similarly both reggies are recruited to the PV in erythrocytes [71]. Preliminary data suggest a similar translocation of reggie-2 to the PV during infection of hepatocytes by Plasmodium berghei [V. Heussler, personal communication]. Considering the vast remodeling of cell function and membrane trafficking in Plasmodium-in- fected cells, hijacking reggie scaffolds and their function might be of particular importance for the parasite.

Some reports hint at a role for reggies in the pathogenesis of neurodegenerative diseases such as Parkinson's and Alzheimer's disease (AD). The formation of senile plaques is a major hallmark of both diseases, which in the case of $\mathrm{AD}$ consist of the peptide $\mathrm{A} \beta$. $\mathrm{A} \beta$ is generated from APP, a transmembrane precursor protein, by successive cleavage by two proteases. Both the $\gamma$-secretase complex as well as the $\beta$-secretase BACE are concentrated in lipid microdomains [72, 73], while their substrate, APP, is largely excluded from lipid rafts $[73,74]$. Thus the partitioning of the enzymes responsible for $\mathrm{A} \beta$ generation (but not their substrate APP) into lipid rafts normally prevents the production of large amounts of $\mathrm{A} \beta$ [75]. Primitive senile plaques in non-demented persons show strong reggie-2 labeling, and in $\mathrm{AD}$ patients both reggies show significantly increased staining of the cortex [76]. An ultrastructural study showed an accumulation of reggie-2 in lysosomes of neurons having neurofibrillary tangles (a second hallmark of AD) [77]. Similarly, in neurons of transgenic mice overexpressing human APP and presenilin- $1, \mathrm{~A} \beta$ and reggie- 2 accumulated in multivesicular bodies [38]. Thus, the progression of AD is accompanied by an accumulation of reggies at sites of $\mathrm{A} \beta$ production and secretion. Similarly, upregulation of reggie-2 expression in the substantia nigra of Parkinson's patients was recently reported [78].

Strong hints link reggie microdomains to the progression of prion diseases. These diseases (e.g. BSE, CJD and scrapie) are caused by an aggregation of misfolded cellular prion protein, a GPI-anchored protein of unknown function. The conversion of the harmless cellular form of the prion protein $\left(\mathrm{PrP}^{\mathrm{c}}\right)$ to the aggregating, disease-causing form, called $\mathrm{PrP}^{\mathrm{Sc}}$, is most probably directed by the misfolded form itself, thus forming an autocatalytic cycle [79]. This conversion process probably takes place in lipid rafts, where the clustering of raft components strongly favors the conversion and aggregation of PrP [80]. We have recently shown that $\mathrm{PrP}^{\mathrm{c}}$ and reggie- 1 and -2 are closely associated at the plasma membrane of lymphocytes [31] and neurons [our own unpublished observations] as shown by co-localization at the LM and EM level and by co-immunoprecipitation. Cross-linking of $\mathrm{PrP}^{\mathrm{c}}$ in lymphocytes leads to its clustering in the region of the preformed reggie cap [31]. Signaling is downregulated by endocytosis of $\mathrm{PrP}^{\mathrm{c}}$ into reggie-positive lysosomes. Clustering of $\mathrm{PrP}^{\mathrm{c}}$ in reggie rafts and subsequent endocytosis into acidic endo-/lysosomes may strongly favor the conversion and aggregation of PrP. Accordingly, a recent report showed that $\mathrm{PrP}^{\mathrm{Sc}}$ is localized in reggie-2positive late endosomes in cells from the central nervous system [81].

Lymphocytes can reach all tissues in the body; this way they contribute to the spreading of prion diseases to dif- 
ferent organs [82]. Thus, clustering of $\mathrm{PrP}$ in reggie microdomains on lymphocytes might play an important role in the spread of prion disease throughout the body. Furthermore, both $\mathrm{PrP}^{\mathrm{c}}$ and reggies are contained in lipid bodies and are apparently also expelled from the cell via lipid-rich vesicles, which may also contibute to the spreading of prion disease [39].

A recent report suggests a role of reggie-1 in cancer invasion and metastasis. Hazarika et al. showed that reggie-1 is highly expressed in metastatic melanomas and that expression of the cytosolic 42-kDa variant of reggie-1 is sufficient to transform non-metastatic SP-2 cells into aggressive, highly metastatic cells [56].

Mutations of the reggie-related protein podocin are implicated in severe renal disorders. However, so far no hereditary disease has been linked to any of the reggies. This means that mutations in reggie genes are either lethal or that reggie function is redundant and can be rescued by other proteins/pathways.

\section{Rivaling caveolae: microdomains scaffolded by reggie and other SPFH proteins}

The concept of lipid rafts providing a basis for the lateral segregation of different membrane-bound processes is definitely auspicious. But details are still controversial, especially concerning the size and protein content of single rafts at steady state, which have proven very hard to characterize [83]. However, the existence and importance of membrane microdomains organized by a protein scaffold is indisputable. The best-characterized examples are caveolae, small $(50-100 \mathrm{~nm})$ flask-shaped invaginations of the plasma membrane which are formed by an oligomeric scaffold of caveolins (reviewed in [28]). Biochemically, the components of caveolae also partition into the lipid raft fraction; thus, caveolae might be considered as specialized rafts. Caveolae have been implicated in the regulation of numerous signaling pathways [28]. Apparently, caveolae and caveolin are also important regulators of lipid and particularly cholesterol homeostasis and trafficking [84]. Moreover, caveolae have been shown to be sites of non-classical endocytosis of GPI-anchored proteins, viruses and other cargo [85], although they are relatively immobile in resting cells due to anchorage to the actin cytoskeleton [86, 87]. Thus, caveolae are accepted as caveolin-based membrane microdomains that provide a laterally constricted environment for specific proteinprotein interactions to take place, with the set of proteins associating and processes depending on caveolae most probably being cell type specific [88].

Given the widespread expression of reggies, the localization of oligomeric reggie clusters at the plasma membrane, their association with lipid rafts, the functional data available and structural similarities to caveolin (see above), a microdomain scaffolding function could also be envisaged for reggies [89]. Oligomeric reggie clusters of approximately $50-100 \mathrm{~nm}$ would then provide a stable basis for facilitating, controlling and segregating proteinprotein interactions at cellular membranes (fig. 2C). The constituents of the protein complexes interacting with reggie scaffolds might depend on the cell type and/or physiological state of the cell. This might explain the variety of binding partners reported for both reggies. In $\mathrm{T}$ cells - which are devoid of caveolae - reggie platforms seem to establish polarity and are essential for assembly of the TCR signaling machinery, which depends on dynamic remodeling of the actin cytoskeleton. In adipocytes reggie microdomains are essential for regulation of Glut4 trafficking after stimulation of the insulin receptor. In neurons, reggies are apparently involved in neurite outgrowth and axon formation. Like caveolae, reggie microdomains might thus be platforms for regulated assembly of specific sets of multi-protein complexes.

As for reggies, the exact cellular functions of the other members of the SPFH protein family remain elusive. The present state of knowledge about these proteins supports the notion that stomatin, podocin and prohibitin also function as specialized microdomain scaffolds.

Stomatin, for example, is widely expressed [90], localizes predominantly to the plasma membrane and intracellular vesicles of the endocytic pathway [91], where it forms oligomers consisting of 9-12 monomers [22]. At the plasma membrane it is detected in clusters in the EM [22, 92], and it associates with lipid rafts [91]. Already in 1998 this association led Prohaska and co-workers to suggest that stomatin oligomers might have a function comparable to caveolin [22]. Stomatin was shown to interact with and regulate members of the degenerin/epithelial $\mathrm{Na}^{+}$channel family in mechanosensory cells of Caenorhabditis elegans [93] and vertebrate neurons [94], and in immunofluorescence stainings these complexes appear as regular puncta at the plasma membrane [95] indicative of microdomains. In other cell types stomatin was implicated in trafficking of Glut1 glucose transporters [96], suggesting again that proteins associating with the microdomain scaffold provided by stomatin clusters might be cell type specific. Stomatin and reggies are both expressed in erythrocytes, although they seem to define different microdomains, as neither can be co-immunoprecipitated with the other. Furthermore, in these cells stomatin but not reggie is found on shedded microvesicles [97, 98].

Podocin is perhaps the most specialized member of the SPFH family, being exclusively expressed in podocytes of the kidney, where it localizes to the glomerular slit diaphragma [20]. Like reggies and stomatin, it associates with lipid rafts [21]. The immunoglobulin (Ig)-superfamily proteins nephrin and neph associate with podocin oligomers/microdomains and become detergent-insolu- 
ble upon association with these complexes [21]. Furthermore, podocin augments nephrin signaling [99]. The podocin-nephrin complexes are linked to the cytoskeleton via the adaptor protein CD2AP, which directly binds to actin [100]. Mutations of the podocin, nephrin or CD2AP genes all cause severe proteinuria, emphasizing the physiological importance of podocin-based microdomains [101].

The prohibitins are mainly localized at the inner membrane of mitochondria [102]. They form ringlike complexes consisting of hetero-oligomers [23, 24]. In mitochondria the prohibitins most probably regulate membrane protein degradation by m-AAA proteases [103, 104], a function very similar to the bacterial members of the SPFH proteins, HflK and HflC, which associate with and regulate the AAA protease FtsH [105]. In addition to their localization at mitochondria, there are reports of prohibitin associating with the $\mathrm{B}$ cell receptor in $\mathrm{B}$ cells $[106,107]$ and with Akt in myogenic cells [108], suggesting extra-mitochondrial functions of the prohibitins. In B cells prohibitin was found to be associated with lipid rafts [107]. Furthermore, they apparently translocate to the nucleus and are implicated in the regulation of gene expression by interaction with $\mathrm{Rb}$ and by regulating $\mathrm{E} 2 \mathrm{~F}$ function $[109,110]$.

Most interestingly, the prohibitins show a mutual dependence similar to that observed for reggies: genetic knockout of prohibitin-1 leads to loss of prohibitin-2 protein and vice versa in yeast [111]. A similar interdependence is also observed for HflK and HflC [105]. This mutual interdependence is another striking similarity between caveolin and the SPFH proteins. Caveolin-1 knock-out mice also lack caveolin-2 protein, although the caveolin2 messenger RNA (mRNA) is still expressed [112], suggesting that the stability of caveolin-2 is linked to the presence of caveolin-1 exactly as observed for reggie- 2 and -1 , the prohibitins and $\mathrm{HflC} / \mathrm{HflK}$. In all these cases the stability of one of the proteins seems to critically depend on the formation of hetero-oligomers with the other. Stomatin, podocin and prohibitin associate - like reggies - with lipid rafts. Targeting of reggies to the plasma membrane and raft association of reggies was shown to be mediated by the SPFH domain $[12,41]$. Thus, lipid raft association of stomatin, podocin and potentially also prohibitin is most probably mediated by the SPFH domain shared by all proteins.

The microdomains formed by SPFH proteins at the plasma membrane are often anchored by interaction with the actin cytoskeleton. Stabilization of reggies in lymphocytes is actin-dependent, and reggie associates closely with cortical actin in many cell types ([41] and our own unpublished observations). Stomatin associates with the cortical actin cytoskeleton [92], and podocin interacts with the actin-anchoring adaptor protein $\mathrm{CD} 2 \mathrm{AP}$ [100]. Scaffolds formed by reggies, stomatin and podocin are thus spatially and temporally stable platforms for the assembly of multiprotein complexes.

It is well accepted that there must be a variety of different microdomains at the plasma membrane of eukaryotic cells, as e.g. a specific association of functionally different GPI-anchored proteins with different microdomains was observed $[113,114]$. Recent evidence shows that microdomains based solely on special lipid compositions (true 'lipid rafts') are small, highly dynamic entities unsuitable to act as signaling scaffolds $[115,116]$. Therefore, specialized microdomains stabilized by an oligomeric protein scaffold might additionally act as guideposts for the fusion of small lipid rafts after stimulation of the cell - as shown for reggies during $\mathrm{T}$ cell activation. In contrast to caveolins, SPFH proteins are widely expressed. Thus, formation of protein-based microdomains by SPFH proteins is probably a feature of eukaryotic cells more common than caveolae.

But in addition to just being a scaffold at the membrane, reggies also have a dynamic, regulatory function. Reggie2 can translocate to the nucleus, where it exhibits a mitogenic, although ill-defined action. Reggie-2 stability is linked via an unknown mechanism to the presence of reggie-1; thus, the more stable, membrane-bound partner controlls the stability of the versatile and mobile partner. The membrane association of reggie- 2 via reversible palmitoylation makes it particularly suited to move between cellular membranes, the cytosol and the nucleus without the need for irreversible modifications such as proteolytic cleavage. It is conceivable that information about processes happening on reggie-based microdomains are thereby conveyed to the nucleus and the gene expression machinery. Similarly, the prohibitins, which also form hetero-oligomers as functional units and exhibit a mutual interdependence of the two proteins, are apparently able to regulate gene expression in the nucleus in addition to their function at the mitochondria and the plasma membrane. Microdomains scaffolded by reggies or other SPFH proteins might therefore on the one hand be stable platforms and on the other hand be dynamic regulatory units with an impact even on gene expression.

Acknowledgments. We thank Eric Rivera-Milla for helpful comments on the manuscript, especially concerning the evolution of SPFH proteins. Work in our laboratory was supported by grants from the Ministerium Forschung, Wissenschaft und Kunst BadenWürttemberg (TSE program), the Deutsche Forschungsgemeinschaft (SFB TR-11) and the Fonds der Chemischen Industrie.

1 Schroeder W. T., Stewart-Galetka S., Mandavilli S., Parry D. A., Goldsmith L. and Duvic M. (1994) Cloning and characterization of a novel epidermal cell surface antigen (ESA). J. Biol. Chem. 269: 19983-19991

2 Hazarika P., Dham N., Patel P., Cho M., Weidner D., Goldsmith L. et al. (1999) Flotillin 2 is distinct from epidermal surface antigen (ESA) and is associated with filopodia formation. J. Cell. Biochem. 75: 147-159 
3 Schulte T., Paschke K. A., Laessing U., Lottspeich F. and Stuermer C. A. (1997) Reggie-1 and reggie-2, two cell surface proteins expressed by retinal ganglion cells during axon regeneration. Development. 124: 577-587

4 Lang D. M., Lommel S., Jung M., Ankerhold R., Petrausch B., Laessing U. et al. (1998) Identification of reggie-1 and reggie-2 as plasmamembrane-associated proteins which cocluster with activated GPI-anchored cell adhesion molecules in non-caveolar micropatches in neurons. J. Neurobiol. 37: 502-523

5 Bickel P. E., Scherer P. E., Schnitzer J. E., Oh P., Lisanti M. P. and Lodish H. F. (1997) Flotillin and epidermal surface antigen define a new family of caveolae-associated integral membrane proteins. J. Biol. Chem. 272: 13793-13802

6 Galbiati F., Volonte D., Goltz J. S., Steele Z., Sen J., Jurcsak J. et al. (1998) Identification, sequence and developmental expression of invertebrate flotillins from Drosophila melanogaster. Gene 210: 229-237

7 Malaga-Trillo E., Laessing U., Lang D. M., Meyer A. and Stuermer C. A. (2002) Evolution of duplicated reggie genes in zebrafish and goldfish. J. Mol. Evol. 54: 235-245

8 Edgar A. J. and Polak J. M. (2001) Flotillin-1: gene structure: cDNA cloning from human lung and the identification of alternative polyadenylation signals. Int. J. Biochem. Cell. Biol. 33: 53-64

9 Borner G. H., Sherrier D. J., Weimar T., Michaelson L. V., Hawkins N. D., Macaskill A. et al. (2005) Analysis of detergent-resistant membranes in Arabidopsis. Evidence for plasma membrane lipid rafts. Plant Physiol. 137: 104-116

10 Cho Y. J., Chema D., Moskow J. J., Cho M., Schroeder W. T., Overbeek P. et al. (1995) Epidermal surface antigen (MS17S1) is highly conserved between mouse and human. Genomics 27: 251-258

11 Tavernarakis N., Driscoll M. and Kyrpides N. C. (1999) The SPFH domain: implicated in regulating targeted protein turnover in stomatins and other membrane-associated proteins. Trends Biochem. Sci. 24: 425-427

12 Morrow I. C., Rea S., Martin S., Prior I. A., Prohaska R., Hancock J. F. et al. (2002) Flotillin-1/reggie-2 traffics to surface raft domains via a novel golgi-independent pathway. Identification of a novel membrane targeting domain and a role for palmitoylation. J. Biol. Chem. 277: 48834-48841

13 Gkantiragas I., Brugger B., Stuven E., Kaloyanova D., Li X. Y., Lohr K. et al. (2001) Sphingomyelin-enriched microdomains at the Golgi complex. Mol. Biol. Cell 12: $1819-1833$

14 Neumann-Giesen C., Falkenbach B., Beicht P., Claasen S., Luers G., Stuermer C. A. et al. (2004) Membrane and raft association of reggie-1/flotillin-2: role of myristoylation, palmitoylation and oligomerization and induction of filopodia by overexpression. Biochem. J. 378: 509-518

15 Miyamoto K., Koshiba S., Inoue M., Kigawa T. and Yokoyama S. (2004) Solution structure of the band 7 domain of the mouse flotillin 2 protein.Protein Data Bank ID1WIN

16 Chen J. anderson J. B., DeWeese-Scott C., Fedorova N. D., Geer L. Y., He S. et al. (2003) MMDB: Entrez's 3D-structure database. Nucleic Acids Res. 31: 474-477

17 Solomon S., Masilamani M., Rajendran L., Bastmeyer M., Stuermer C. A. and Illges H. (2002) The lipid raft microdomain-associated protein reggie-1/flotillin-2 is expressed in human B cells and localized at the plasma membrane and centrosome in PBMCs. Immunobiology 205: 108-119

18 Lopez-Casas P. P. and del Mazo J. (2003) Regulation of flotillin-1 in the establishment of NIH-3T3 cell-cell interactions. FEBS Lett. 555: 223-228

19 Salzer U., Ahorn H. and Prohaska R. (1993) Identification of the phosphorylation site on human erythrocyte band 7 integral membrane protein: implications for a monotopic protein structure. Biochim. Biophys. Acta. 1151: 149-152
20 Roselli S., Gribouval O., Boute N., Sich M., Benessy F., Attie T. et al. (2002) Podocin localizes in the kidney to the slit diaphragm area. Am. J. Pathol. 160: 131-139

21 Huber T. B., Simons M., Hartleben B., Sernetz L., Schmidts M., Gundlach E. et al. (2003) Molecular basis of the functional podocin-nephrin complex: mutations in the NPHS2 gene disrupt nephrin targeting to lipid raft microdomains. Hum. Mol. Genet. 12: 3397-3405

22 Snyers L., Umlauf E. and Prohaska R. (1998) Oligomeric nature of the integral membrane protein stomatin. J. Biol. Chem. 273: $17221-17226$

23 Back J. W., Sanz M. A., De Jong L., De Koning L. J., Nijtmans L. G., De Koster C. G. et al. (2002) A structure for the yeast prohibitin complex: structure prediction and evidence from chemical crosslinking and mass spectrometry. Protein Sci. 11: 2471-2478

24 Tatsuta T., Model K. and Langer T. (2005) Formation of membrane-bound ring complexes by prohibitins in mitochondria. Mol. Biol. Cell. 16: 248-259

25 Okamoto T., Schlegel A., Scherer P. E. and Lisanti M. P. (1998) Caveolins, a family of scaffolding proteins for organizing 'preassembled signaling complexes' at the plasma membrane. J. Biol. Chem. 273: 5419-5422

26 Dietzen D. J., Hastings W. R. and Lublin D. M. (1995) Caveolin is palmitoylated on multiple cysteine residues. Palmitoylation is not necessary for localization of caveolin to caveolae. J. Biol. Chem. 270: 6838-6842

27 Monier S., Parton R. G., Vogel F., Behlke J., Henske A. and Kurzchalia T. V. (1995) VIP21-caveolin, a membrane protein constituent of the caveolar coat, oligomerizes in vivo and in vitro. Mol. Biol. Cell 6: 911-927

28 Cohen A. W., Hnasko R., Schubert W. and Lisanti M. P. (2004) Role of caveolae and caveolins in health and disease. Physiol. Rev. 84: 1341-1379

29 Stuermer C. A., Lang D. M., Kirsch F., Wiechers M., Deininger S. O. and Plattner H. (2001) Glycosylphosphatidyl inositol-anchored proteins and fyn kinase assemble in noncaveolar plasma membrane microdomains defined by reggie1 and -2. Mol. Biol. Cell 12: 3031-3045

30 Kokubo H., Helms J. B., Ohno-Iwashita Y., Shimada Y., Horikoshi Y. and Yamaguchi H. (2003) Ultrastructural localization of flotillin-1 to cholesterol-rich membrane microdomains, rafts, in rat brain tissue. Brain Res. 965: 8390

31 Stuermer C. A., Langhorst M. F., Wiechers M. F., Legler D. F., Hannbeck von Hanwehr S., Guse A. H. et al. (2004) $\mathrm{PrPc}$ capping in $\mathrm{T}$ cells promotes its association with the lipid raft proteins reggie-1 and reggie-2 and leads to signal transduction. FASEB J. Express article 10.1096/fj.042150fje

32 Volonte D., Galbiati F., Li S., Nishiyama K., Okamoto T. and Lisanti M. P. (1999) Flotillins/cavatellins are differentially expressed in cells and tissues and form a hetero-oligomeric complex with caveolins in vivo. Characterization and epitopemapping of a novel flotillin-1 monoclonal antibody probe. J. Biol. Chem. 274: 12702-12709

33 Evans W. E. 4th., Coyer R. L., Sandusky M. F., Van Fleet M. J., Moore J. G. and Nyquist S. E. (2003) Characterization of membrane rafts isolated from rat sertoli cell cultures: caveolin and flotillin-1 content. J. Androl. 24: 812-821

34 Pandur P. D., Dirksen M. L., Moore K. B. and Moody S. A. (2004) Xenopus flotillin 1, a novel gene highly expressed in the dorsal nervous system. Dev. Dyn. 231: 881-887

35 Souto R. P., Vallega G., Wharton J., Vinten J., Tranum-Jensen J. and Pilch P. F. (2003) Immunopurification and characterization of rat adipocyte caveolae suggest their dissociation from insulin signaling. J. Biol. Chem. 278: 18321-18329

36 Gagescu R., Demaurex N., Parton R. G., Hunziker W., Huber L. A. and Gruenberg J. (2000) The recycling endosome of 
Madin-Darby canine kidney cells is a mildly acidic compartment rich in raft components. Mol. Biol. Cell 11: 27752791

37 de Gassart A., Geminard C., Fevrier B., Raposo G. and Vidal M. (2003) Lipid raft-associated protein sorting in exosomes. Blood 102: 4336-4344

38 Langui D., Girardot N., El Hachimi K. H., Allinquant B., Blanchard V., Pradier L. et al. (2004) Subcellular topography of neuronal Abeta peptide in APPxPS1 transgenic mice. Am. J. Pathol. 165: 1465-1477

39 Reuter A., Binkle U., Stuermer C. A. and Plattner H. (2004) $\operatorname{PrP}(\mathrm{c})$ and reggies/flotillins are contained in and released via lipid-rich vesicles in Jurkat T cells. Cell. Mol. Life Sci. 61: 2092-2099

40 Liu P., Ying Y., Zhao Y., Mundy D. I., Zhu M. and Anderson R. G. (2004) Chinese hamster ovary K2 cell lipid droplets appear to be metabolic organelles involved in membrane traffic. J. Biol. Chem. 279: 3787-3792

41 Liu J., Deyoung S. M., Zhang M., Dold L. H. and Saltiel A. R. (2005) The stomatin/prohibitin/flotillin/HflK/C domain of flotillin-1 contains distinct sequences that direct plasma membrane localization and protein interactions in 3T3-L1 adipocytes. J. Biol. Chem. 280: 16125-16134

42 Slaughter N., Laux I., Tu X., Whitelegge J., Zhu X., Effros R. et al. (2003) The flotillins are integral membrane proteins in lipid rafts that contain TCR-associated signaling components: implications for T-cell activation. Clin. Immunol. 108: 138151

43 Garin J., Diez R., Kieffer S., Dermine J. F., Duclos S., Gagnon E. et al. (2001) The phagosome proteome: insight into phagosome functions. J. Cell. Biol. 152: 165-180

44 Dermine J. F., Duclos S., Garin J., St-Louis F., Rea S., Parton R. G. et al. (2001) Flotillin-1-enriched lipid raft domains accumulate on maturing phagosomes. J. Biol. Chem. 276: $18507-18512$

45 Santamaria A., Castellanos E., Gomez V., Benedit P., RenauPiqueras J., Morote J. et al. (2005) PTOV1 enables the nuclear translocation and mitogenic activity of flotillin-1, a major protein of lipid rafts. Mol. Cell. Biol. 25: 1900-1911

46 Bonnon C., Goutebroze L., Denisenko-Nehrbass N., Girault J. A. and Faivre-Sarrailh C. (2003) The paranodal complex of F3/contactin and caspr/paranodin traffics to the cell surface via a non-conventional pathway. J. Biol. Chem. 278: 4833948347

47 Apolloni A., Prior I. A., Lindsay M., Parton R. G. and Hancock J. F. (2000) H-ras but not K-ras traffics to the plasma membrane through the exocytic pathway. Mol. Cell. Biol. 20: 2475-2487

48 Watson R. T., Furukawa M., Chiang S. H., Boeglin D., Kanzaki M., Saltiel A. R. et al. (2003) The exocytotic trafficking of TC10 occurs through both classical and nonclassical secretory transport pathways in 3T3L1 adipocytes. Mol. Cell. Biol. 23: $961-974$

49 Bijlmakers M. J. and Marsh M. (2003) The on-off story of protein palmitoylation. Trends Cell Biol. 13: 32-42

50 Mairhofer M., Steiner M., Mosgoeller W., Prohaska R. and Salzer U. (2002) Stomatin is a major lipid-raft component of platelet alpha granules. Blood 100: 897-904

51 Ha H., Kwak H. B., Lee S. K., Na D. S., Rudd C. E., Lee Z. H. et al. (2003) Membrane rafts play a crucial role in receptor activator of nuclear factor kappaB signaling and osteoclast function. J. Biol. Chem. 278: 18573-18580

52 von Philipsborn A. C., Ferrer-Vaquer A., Rivera-Milla E., Stuermer C. A. and Malaga-Trillo E. (2005) Restricted expression of reggie genes and proteins during early zebrafish development. J. Comp. Neurol. 482: 257-272

53 Deininger S. O., Rajendran L., Lottspeich F., Przybylski M., Illges H., Stuermer C. A. et al. (2003) Identification of teleost Thy-1 and association with the microdomain/lipid raft reggie proteins in regenerating CNS axons. Mol. Cell. Neurosci. 22: 544-554

54 Reuter A., Málaga-Trillo E., Binkle U., Rivera-Milla E., Beltre R., Zhou Y. et al. (2004) Evolutionary analysis and expression of teleost Thy-1. Zebrafish 1: 191-201

55 Bared S. M., Buechler C., Boettcher A., Dayoub R., Sigruener A., Grandl M. et al. (2004) Association of ABCA1 with syntaxin 13 and flotillin-1 and enhanced phagocytosis in tangier cells. Mol. Biol. Cell. 15: 5399-5407

56 Hazarika P., McCarty M. F., Prieto V. G., George S., Babu D., Koul D. et al. (2004) Up-regulation of Flotillin-2 is associated with melanoma progression and modulates expression of the thrombin receptor protease activated receptor 1 . Cancer Res. 64: 7361-7369

57 Wakasugi K., Nakano T., Kitatsuji C. and Morishima I. (2004) Human neuroglobin interacts with flotillin-1, a lipid raft microdomain-associated protein. Biochem. Biophys. Res. Commun. 318: 453-460

58 Kimura A., Baumann C. A., Chiang S. H. and Saltiel A. R. (2001) The sorbin homology domain: a motif for the targeting of proteins to lipid rafts. Proc. Natl. Acad. Sci. USA 98: 9098-9103

59 Kioka N., Ueda K. and Amachi T. (2002) Vinexin, CAP/ponsin, ArgBP2: a novel adaptor protein family regulating cytoskeletal organization and signal transduction. Cell Struct. Funct. 27: 1-7

60 Baumann C. A., Ribon V., Kanzaki M., Thurmond D. C., Mora S., Shigematsu S. et al. (2000) CAP defines a second signalling pathway required for insulin-stimulated glucose transport. Nature 407: 202-207

61 Haglund K., Ivankovic-Dikic I., Shimokawa N., Kruh G. D. and Dikic I. (2004) Recruitment of Pyk2 and Cbl to lipid rafts mediates signals important for actin reorganization in growing neurites. J. Cell Sci. 117: 2557-2568

$62 \mathrm{Tu}$ X., Huang A., Bae D., Slaughter N., Whitelegge J., Crother T. et al. (2004) Proteome analysis of lipid rafts in Jurkat cells characterizes a raft subset that is involved in NF-kappaB activation. J. Proteome Res. 3: 445-454

63 Rajendran L., Masilamani M., Solomon S., Tikkanen R., Stuermer C. A., Plattner H. et al. (2003) Asymmetric localization of flotillins/reggies in preassembled platforms confers inherent polarity to hematopoietic cells. Proc. Natl. Acad. Sci. USA 100: $8241-8246$

64 Rodgers W., Farris D. and Mishra S. (2005) Merging complexes: properties of membrane raft assembly during lymphocyte signaling. Trends Immunol. 26: 97-103

65 Valensin S., Paccani S. R., Ulivieri C., Mercati D., Pacini S., Patrussi L. et al. (2002) F-actin dynamics control segregation of the TCR signaling cascade to clustered lipid rafts. Eur. J. Immunol. 32: 435-446

66 Villalba M., Bi K., Rodriguez F., Tanaka Y., Schoenberger S. and Altman A. (2001) Vav1/Rac-dependent actin cytoskeleton reorganization is required for lipid raft clustering in T cells. $\mathrm{J}$. Cell. Biol. 155: 331-338

67 Rodgers W. and Zavzavadjian J. (2001) Glycolipid-enriched membrane domains are assembled into membrane patches by associating with the actin cytoskeleton. Exp. Cell Res. 267: 173-183

68 Simons K. and Ehehalt R. (2002) Cholesterol, lipid rafts and disease. J. Clin. Invest. 110: 597-603

69 Samuel B. U., Mohandas N., Harrison T., McManus H., Rosse W., Reid M. et al. (2001) The role of cholesterol and glycosylphosphatidylinositol-anchored proteins of erythrocyte rafts in regulating raft protein content and malarial infection. J. Biol. Chem. 276: 29319-29329

70 Lauer S., VanWye J., Harrison T., McManus H., Samuel B. U., Hiller N. L. et al. (2000) Vacuolar uptake of host components, and a role for cholesterol and sphingomyelin in malarial infection. EMBO J. 19: 3556-3564 
71 Murphy S. C., Samuel B. U., Harrison T., Speicher K. D., Speicher D. W., Reid M. E. et al. (2004) Erythrocyte detergent-resistant membrane proteins: their characterization and selective uptake during malarial infection. Blood 103: 1920-1928

72 Vetrivel K. S., Cheng H., Lin W., Sakurai T., Li T., Nukina N. et al. (2004) Association of gamma-secretase with lipid rafts in post-Golgi and endosome membranes. J. Biol. Chem. 279: 44945-44954

73 Abad-Rodriguez J., Ledesma M. D., Craessaerts K., Perga S., Medina M., Delacourte A. et al. (2004) Neuronal membrane cholesterol loss enhances amyloid peptide generation. J. Cell. Biol. 167: 953-960

74 Parkin E. T., Tan F., Skidgel R. A., Turner A. J. and Hooper N. M. (2003) The ectodomain shedding of angiotensin-converting enzyme is independent of its localisation in lipid rafts. J. Cell Sci. 116: 3079-3087

75 Kaether C. and Haass C. (2004) A lipid boundary separates APP and secretases and limits amyloid beta-peptide generation. J. Cell. Biol. 167: 809-812

76 Kokubo H., Lemere C. A. and Yamaguchi H. (2000) Localization of flotillins in human brain and their accumulation with the progression of Alzheimer's disease pathology. Neurosci. Lett. 290: 93-96

77 Girardot N., Allinquant B., Langui D., Laquerriere A., Dubois B., Hauw J. J. et al. (2003) Accumulation of flotillin-1 in tangle-bearing neurones of Alzheimer's disease. Neuropathol. Appl. Neurobiol. 29: 451-461

78 Jacobowitz D. M. and Kallarakal A. T. (2004) Flotillin-1 in the substantia nigra of the Parkinson brain and a predominant localization in catecholaminergic nerves in the rat brain. Neurotox. Res. 6: 245-257

79 Weissmann C. (2004) The state of the prion. Nat. Rev. Microbiol. 2: $861-871$

80 Kazlauskaite J. and Pinheiro T. J. (2005) Aggregation and fibrillization of prions in lipid membranes. In: Lipids, Rafts and Traffic, pp. 211-222, McIlhinney J. and Hooper N. (eds.), Biochem. Soc. Symp. vol. 72, Portland Press, London.

81 Pimpinelli F., Lehmann S. and Maridonneau-Parini I. (2005) The scrapie prion protein is present in flotillin-1-positive vesicles in central- but not peripheral-derived neuronal cell lines. Eur. J. Neurosci. 21: 2063-2072

82 Heikenwalder M., Zeller N., Seeger H., Prinz M., Klohn P. C., Schwarz P. et al. (2005) Chronic lymphocytic inflammation specifies the organ tropism of prions. Science 307: 11071110

83 Munro S. (2003) Lipid rafts: elusive or illusive? Cell 115: 377-388

84 Fielding C. J. and Fielding P. E. (2001) Caveolae and intracellular trafficking of cholesterol. Adv. Drug Deliv. Rev. 49: 251-264

85 Parton R. G. and Richards A. A. (2003) Lipid rafts and caveolae as portals for endocytosis: new insights and common mechanisms. Traffic 4: 724-738

86 Thomsen P., Roepstorff K., Stahlhut M. and van Deurs B. (2002) Caveolae are highly immobile plasma membrane microdomains, which are not involved in constitutive endocytic trafficking. Mol. Biol. Cell 13: 238-250

87 van Deurs B., Roepstorff K., Hommelgaard A. M. and Sandvig K. (2003) Caveolae: anchored, multifunctional platforms in the lipid ocean. Trends Cell Biol. 13: 92-100

88 Parton R. G. (2003) Caveolae - from ultrastructure to molecular mechanisms. Nat. Rev. Mol. Cell. Biol. 4: 162-167

89 Stuermer C. A. and Plattner H. (2005).The 'lipid raft' microdomain proteins reggie-1 and reggie-2 (flotillins) are scaffolds for protein interaction and signalling. In: Lipids, Rafts and Traffic, pp. 109-118, McIlhinney J. and Hooper N. (eds.), Biochem. Soc. Symp. vol. 72, Portland Press, London.

90 Gallagher P. G. and Forget B. G. (1995) Structure, organization and expression of the human band $7.2 \mathrm{~b}$ gene, a candidate gene for hereditary hydrocytosis. J. Biol. Chem. 270: 2635826363

91 Snyers L., Umlauf E. and Prohaska R. (1999) Association of stomatin with lipid-protein complexes in the plasma membrane and the endocytic compartment. Eur. J. Cell. Biol. 78: $802-812$

92 Snyers L., Thines-Sempoux D. and Prohaska R. (1997) Colocalization of stomatin (band 7.2b) and actin microfilaments in UAC epithelial cells. Eur. J. Cell. Biol. 73: 281-285

93 Goodman M. B., Ernstrom G. G., Chelur D. S., O'Hagan R., Yao C. A. and Chalfie M. (2002) MEC-2 regulates C. elegans $\mathrm{DEG} / \mathrm{ENaC}$ channels needed for mechanosensation. Nature 415: $1039-1042$

94 Price M. P., Thompson R. J., Eshcol J. O., Wemmie J. A. and Benson C. J. (2004) Stomatin modulates gating of acid-sensing ion channels. J. Biol. Chem. 279: 53886-53891

95 Zhang S., Arnadottir J., Keller C., Caldwell G. A., Yao C. A. and Chalfie M. (2004) MEC-2 is recruited to the putative mechanosensory complex in C. elegans touch receptor neurons through its stomatin-like domain. Curr. Biol. 14: 1888-1896

96 Zhang J. Z., Abbud W., Prohaska R. and Ismail-Beigi F. (2001) Overexpression of stomatin depresses GLUT-1 glucose transporter activity. Am. J. Physiol.Cell. Physiol. 280: C12771283

97 Salzer U. and Prohaska R. (2001) Stomatin, flotillin-1 and flotillin-2 are major integral proteins of erythrocyte lipid rafts. Blood 97: 1141-1143

98 Salzer U., Hinterdorfer P., Hunger U., Borken C. and Prohaska R. (2002) Ca(++)-dependent vesicle release from erythrocytes involves stomatin-specific lipid rafts, synexin (annexin VII) and sorcin. Blood 99: 2569-2577

99 Huber T. B., Kottgen M., Schilling B., Walz G. and Benzing T. (2001) Interaction with podocin facilitates nephrin signaling. J. Biol. Chem. 276: 41543-41546

100 Schwarz K., Simons M., Reiser J., Saleem M. A., Faul C., Kriz W. et al. (2001) Podocin, a raft-associated component of the glomerular slit diaphragm, interacts with CD2AP and nephrin. J. Clin. Invest. 108: 1621-1629

101 Miner J. H. (2002) Focusing on the glomerular slit diaphragm: podocin enters the picture. Am. J. Pathol. 160: 3-5

102 Ikonen E., Fiedler K., Parton R. G. and Simons K. (1995) Prohibitin, an antiproliferative protein, is localized to mitochondria. FEBS Lett. 358: 273-277

103 Steglich G., Neupert W. and Langer T. (1999) Prohibitins regulate membrane protein degradation by the m-AAA protease in mitochondria. Mol. Cell. Biol. 19: 3435-3442

104 Nijtmans L. G., de Jong L., Artal Sanz M., Coates P. J., Berden J. A., Back J. W. et al. (2000) Prohibitins act as a membranebound chaperone for the stabilization of mitochondrial proteins. EMBO J. 19: 2444-2451

105 Nijtmans L. G., Artal S. M., Grivell L. A. and Coates P. J. (2002) The mitochondrial PHB complex: roles in mitochondrial respiratory complex assembly, ageing and degenerative disease. Cell. Mol. Life. Sci. 59: 143-155

106 Terashima M., Kim K. M., Adachi T., Nielsen P. J., Reth M., Kohler G. et al. (1994) The IgM antigen receptor of B lymphocytes is associated with prohibitin and a prohibitin-related protein. EMBO J. 13: 3782-3792

107 Mielenz D., Vettermann C., Hampel M., Lang C., Avramidou A., Karas M. et al. (2005) Lipid rafts associate with intracellular B cell receptors and exhibit a B cell stage-specific protein composition. J. Immunol. 174: 3508-3517

108 Sun L., Liu L., Yang X. J. and Wu Z. (2004) Akt binds prohibitin 2 and relieves its repression of MyoD and muscle differentiation. J. Cell Sci. 117: 3021-3029

109 Wang S., Nath N., Adlam M. and Chellappan S. (1999) Prohibitin, a potential tumor suppressor, interacts with $\mathrm{RB}$ and regulates E2F function. Oncogene 18: 3501-3510 
110 Wang S., Nath N., Fusaro G. and Chellappan S. (1999) Rb and prohibitin target distinct regions of E2F1 for repression and respond to different upstream signals. Mol. Cell. Biol. 19: $7447-7460$

111 Berger K. H. and Yaffe M. P. (1998) Prohibitin family members interact genetically with mitochondrial inheritance components in Saccharomyces cerevisiae. Mol. Cell. Biol. 18: 4043-4052

112 Drab M., Verkade P., Elger M., Kasper M., Lohn M., Lauterbach B. et al. (2001) Loss of caveolae, vascular dysfunction, and pulmonary defects in caveolin-1 gene-disrupted mice. Science 293: 2449-2452

113 Madore N., Smith K. L., Graham C. H., Jen A., Brady K., Hall S. et al. (1999) Functionally different GPI proteins are orga- nized in different domains on the neuronal surface. EMBO J. 18: 6917-6926

114 Schnitzer J. E., McIntosh D. P., Dvorak A. M., Liu J. and Oh P. (1995) Separation of caveolae from associated microdomains of GPI-anchored proteins. Science 269: 1435-1439

115 Sharma P., Varma R., Sarasij R. C., Ira, Gousset K., Krishnamoorthy G. et al. (2004) Nanoscale organization of multiple GPI-anchored proteins in living cell membranes. Cell 116: 577-589

116 Subczynski W. K. and Kusumi A. (2003) Dynamics of raft molecules in the cell and artificial membranes: approaches by pulse EPR spin labeling and single molecule optical microscopy. Biochim. Biophys. Acta 1610: 231-243

\section{To access this journal online: \\ (4P) http://www.birkhauser.ch}

